\title{
Statistical analysis of air conditioning peak loads of multiple dwellings
}

\author{
Tetsushi Ono ${ }^{1 *}$, Aya Hagishima ${ }^{1}$, Jun Tanimoto ${ }^{1}$, Sheikh Ahmad Zaki ${ }^{2}$, Naja Aqilah Hisham ${ }^{2}$ \\ ${ }^{1}$ Interdisciplinary Graduate School of Science Engineering (IGSES), Kyushu University Kasuga-koen 6-1, Kasuga-shi, Fukuoka, 816- \\ 8580, Japan \\ ${ }^{2}$ Malaysia-Japan International Institute of Technology (MJIIT), Universiti Teknologi Malaysia Jalan Semarak, 54100 Kuala Lumpur, \\ Malaysia
}

\begin{abstract}
Evaluation of the aggregated air-conditioning load of multiple dwellings is important for demand response through the optimum control of numerous air-conditioners $(\mathrm{A} / \mathrm{Cs})$, for development of smart-city or smart-community technologies. However, past studies have mainly focused on the characteristics of $\mathrm{A} / \mathrm{C}$ load in a single household. With this background, the authors conducted statistical analysis of time-series data for A/C electricity consumption in 489 dwellings in Osaka, Japan, and 20 dwellings in Kuala Lumpur, Malaysia to grasp the feature of aggregated $\mathrm{A} / \mathrm{C}$ load of multiple dwellings. The findings of this analysis are followings: 1) the aggregated $\mathrm{A} / \mathrm{C}$ load peak per dwelling decreased by almost $50 \%$ as the number of dwellings increased from 1 to 10 , due to the offset of the diverse time-patterns of $\mathrm{A} / \mathrm{C}$ load. 2) The occurrence of the top $2.5 \% \mathrm{~A} / \mathrm{C}$ load shows strong time and date dependency for an $\mathrm{A} / \mathrm{C}$ load aggregated by many dwellings:
\end{abstract}

\section{Introduction}

Due to the global warming, energy saving and emission reduction of greenhouse gasses have become a pressing issue for the international society. In the residential sector, the improvement of energy efficiency of both energy supply systems and buildings is essential. With this in mind, the aptly named smart city technologies, including renewable energy sources and energy management systems have been developed intensively. Since the power generation of renewable energy sources is unstable, the gap between demand and supply is a critical factor. Therefore, demand side energy management has captured increasing attention. As an airconditioning $(\mathrm{A} / \mathrm{C})$ system is a utility that consumes a large amount of energy and significantly affects the load curve, the understanding of the stochastic features of a time-series demand for $\mathrm{A} / \mathrm{C}$ is important to achieve an effective demand response. However, the estimation of an actual stochastic $\mathrm{A} / \mathrm{C}$ load, especially in the residential sector, is highly challenging due to the diversity of the occupants' schedules and behaviours toward $\mathrm{A} / \mathrm{C}$ operations [1].

Over the recent decades, there have been many field surveys on the occupants behaviours relating to $\mathrm{A} / \mathrm{C}$ load. Many of studies conducted in Western countries have suggested that the probabilities of the occupants' actions, such as opening a window and using solar shading, can be modelled through the logistic functions of environmental variables such as indoor air temperature $[2,3]$. On the other hand, in many Asian countries experiencing hot summers, wall hanging room air conditioners are more popular than the district heating and cooling system in residential buildings, thus, many studies on the behaviour of $\mathrm{A} / \mathrm{C}$ use have been intensively conducted $[4,5]$. Furthermore, in recent years, the data collection of timeseries electricity consumption, even in hundreds of dwellings, with high time resolution has become simple due to the deployment of smart meters. Ren et al. and Kindaichi et al. used a data mining technique to analyze the time-varying $\mathrm{A} / \mathrm{C}$ load of each household along with occupant behaviour $[6,7]$.

It is noteworthy that most of these studies focus on the features of $\mathrm{A} / \mathrm{C}$ load of a single household even though they used data of multiple dwellings. The findings of such studies are meaningful for the development of smarthouse technologies. In contrast, the statistical features of aggregated $\mathrm{A} / \mathrm{C}$ load curve of multiple dwellings have not been well investigated. Considering a scenario of smartcity or smart-community with the interchange of power generated by renewable energy sources, the knowledge about aggregated load curve including $\mathrm{A} / \mathrm{C}$ load is highly important in order to implement demand-side

\footnotetext{
* Corresponding author: tetsushi.112231@gmail.com
} 
Table 1. A summary of the A/C electricity consumption datasets used in this study for statistical analysis.

\begin{tabular}{c|c|c}
\hline & Japan & Malaysia \\
\hline City & Osaka & Kuala Lumpur \\
\hline Building type & Multiple dwelling complex & Multiple dwelling complex \\
\hline Number of dwellings & 486 & Reinforced concrete \\
\hline Structure & Reinforced concrete & None \\
\hline $\begin{array}{c}\text { Installed equipment } \\
\text { for all dwellings }\end{array}$ & $\begin{array}{c}\text { A/C in living room, } \\
\text { Gas floor heating system }\end{array}$ & $\begin{array}{c}48 \text { days to 1 year } \\
\text { Measurement period }\end{array}$ \\
\hline (Jan 2013 to Dec 2014) & (Mar 2016 to Aug 2017) \\
\hline Measurement interval & 1 min & min \\
\hline
\end{tabular}

management targeting many $\mathrm{A} / \mathrm{C}$ units of multiple dwellings.

Under these circumstances, the authors conducted a statistical analysis of time series data for A/C electricity consumption in residential buildings to grasp the feature of aggregated $\mathrm{A} / \mathrm{C}$ load of multiple dwellings. The energy consumption data collected in residential buildings located in two cities, namely, Osaka, Japan and KualaLumpur (KL), Malaysia were used for the analysis. These two cities have contrasting climate conditions, however, there is a commonality between them in the significant fraction of $\mathrm{A} / \mathrm{Cs}$ to the total household energy. In this paper, the authors mainly discuss about the feature of peak of the aggregated $\mathrm{A} / \mathrm{C}$ loads of multiple dwellings.

\section{Summary of the measurement}

A summary of the datasets used for statistical analysis is shown in Table 1. Note that the datasets are different from those in our previous studies [8,9]. The data in Japan was recorded in 586 dwellings in Osaka $\left(34^{\circ} 41^{\prime} \mathrm{N}, 135^{\circ} 30^{\prime} \mathrm{E}\right)$. from 1 January 2013 to 31 December 2014. All dwellings are in the same large housing complex built of reinforced concrete. Most of the target dwellings consisted of three

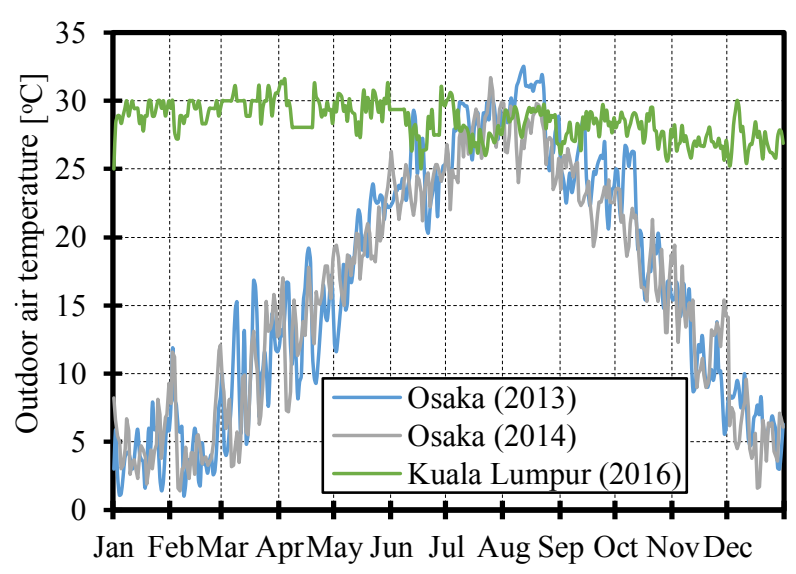

Fig 1. Annual variation in the daily average of outdoor air temperature, observed in Osaka and KL bed rooms and a living room connected with a dining room and kitchen, other layouts include two or four bed rooms. The electricity consumption of various branches in a distribution board were measured at 1-min intervals, the branches themselves were exclusive to each $\mathrm{A} / \mathrm{C}$ unit. Note that the same type of inverter-controlled $\mathrm{A} / \mathrm{C}$ with an annual performance factor (APF) of 4.7 to 6.7, depending on the rated capacity, are installed in the living rooms of all dwellings in Osaka. Furthermore, all the dwellings in Osaka are equipped with gas floor heating systems. Based on the preliminary investigation, the data of 489 dwellings was selected for the following analysis.

On the other hand, the data in Malaysia was collected in 20 dwellings located in the same housing complex in Kuala Lumpur $\left(3^{\circ} 08^{\prime} \mathrm{N}, 101^{\circ} 42^{\prime} \mathrm{E}\right)$. All the dwelling units had three bed rooms, a living room, a dining room, and a kitchen. The measurement periods varied among the target dwellings from 48 days to 1 year. The electricity consumption of A/Cs were measured at a 1-min interval by energy monitoring systems developed by OWL [10].

Figure 1 shows the annual variations in the daily average of outdoor air temperature in 2013 and 2014 in Osaka, and 2016 in Kuala Lumpur (KL), respectively. Note that the outdoor air temperature of KL located on the equator is relatively constant year-round; in contrast, Osaka experiences a distinct seasonal cycle. Despite the different climate zones of the two regions, the outdoor air temperatures in Osaka from July to August are similar those in KL. In addition, since the hours of sunlight in August 2014 were extremely short, $60 \%$ less than that in 2013, only the dataset of Osaka in 2013 was used for our analysis.

Figure 2 shows the proportions of the number of $\mathrm{A} / \mathrm{Cs}$ in each target dwelling in the two cities. Since the number of $\mathrm{A} / \mathrm{Cs}$ equipped in each dwelling in Osaka is not disclosed, it is estimated by the electricity consumption measured at the exclusive branches of each $\mathrm{A} / \mathrm{C}$ unit. If the measured electricity consumption is over $65 \mathrm{~W}$ for more than one hour per year, the branch is classified as connected to an $\mathrm{A} / \mathrm{C}$. This figure shows that around $80 \%$ of the dwellings have two or three A/Cs in Osaka, and the average number of $\mathrm{A} / \mathrm{Cs}$ in the target dwellings in Osaka 
was 2.52, which is close to the average number of people in Japanese families which is 2.46 [11]. On the other hand, $60 \%$ of the dwellings in $\mathrm{KL}$ had only one $\mathrm{A} / \mathrm{C}$ and no dwelling had more than three $\mathrm{A} / \mathrm{Cs}$. The average number of $\mathrm{A} / \mathrm{Cs}$ of the target dwellings in KL was only 1.5 , even though the average number of people of the target dwellings reached five. This indicates that the occupants in $\mathrm{KL}$ shared a few $\mathrm{A} / \mathrm{Cs}$ among large families.

\section{Daily variation in A/C usage of the two cities}

We firstly analysed the basic statistics of $\mathrm{A} / \mathrm{C}$ usage such as when occupants use $\mathrm{A} / \mathrm{Cs}$ and how it varies among household. Figure 3 shows daily variations in the fraction of households using $\mathrm{A} / \mathrm{C}$ in Osaka and $\mathrm{KL}$. The upper figures indicate the variations of $\mathrm{A} / \mathrm{C}$ in living room, and the lower ones show those of $\mathrm{A} / \mathrm{C}$ in bed rooms. In Osaka, the ratio of households using $\mathrm{A} / \mathrm{Cs}$ for cooling in living rooms gradually increases during the day and reaches a peak around $9 \mathrm{pm}$, followed by a rapid decrease until 3-5 am. On the other hand, the usage in bedrooms exhibits a peak at midnight and very few dwellings used A/Cs during the day. This pattern is similar to those of bed rooms and living rooms in KL. This suggests that the occupants in Malaysia rarely used A/Cs throughout the day, and tended to operate $\mathrm{A} / \mathrm{Cs}$ in the living room at midnight to sleep

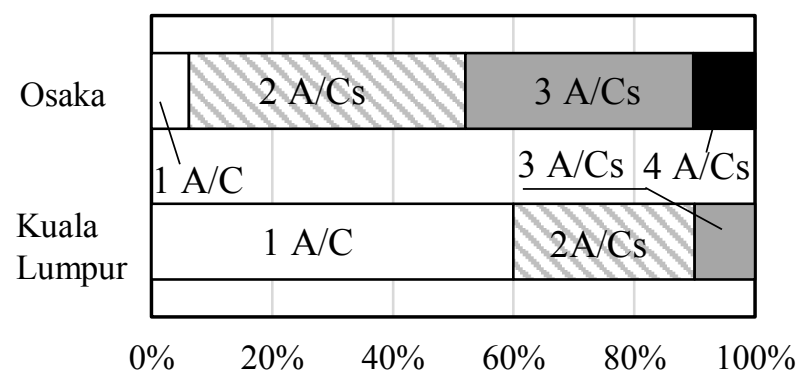

Fig 2. Proportions of the number of $\mathrm{A} / \mathrm{C}$ units in the target dwellings.

comfortably. In fact, according to the supplementary interview conducted on the occupants in KL, air conditioners that were installed in living room were frequently operated at night to cool the connected bedrooms that lacked air conditioners [8]. On the other hand, the profile for heating in Osaka shows a different tendency. Notice the data of $\mathrm{A} / \mathrm{Cs}$ in living rooms, the value of $\mathrm{A} / \mathrm{C}$ usage has a peak in the morning as well as at 8-9 pm, probably due to the low outdoor temperature in the morning. In contrast, the ratio observed for $\mathrm{A} / \mathrm{C}$ usage in bed rooms is less than 0.1 even at night. This implies that the occupants in Osaka exhibit an adaptation behaviour by utilizing high-insulation bedding to reduce dependency on $\mathrm{A} / \mathrm{C}$ heating.
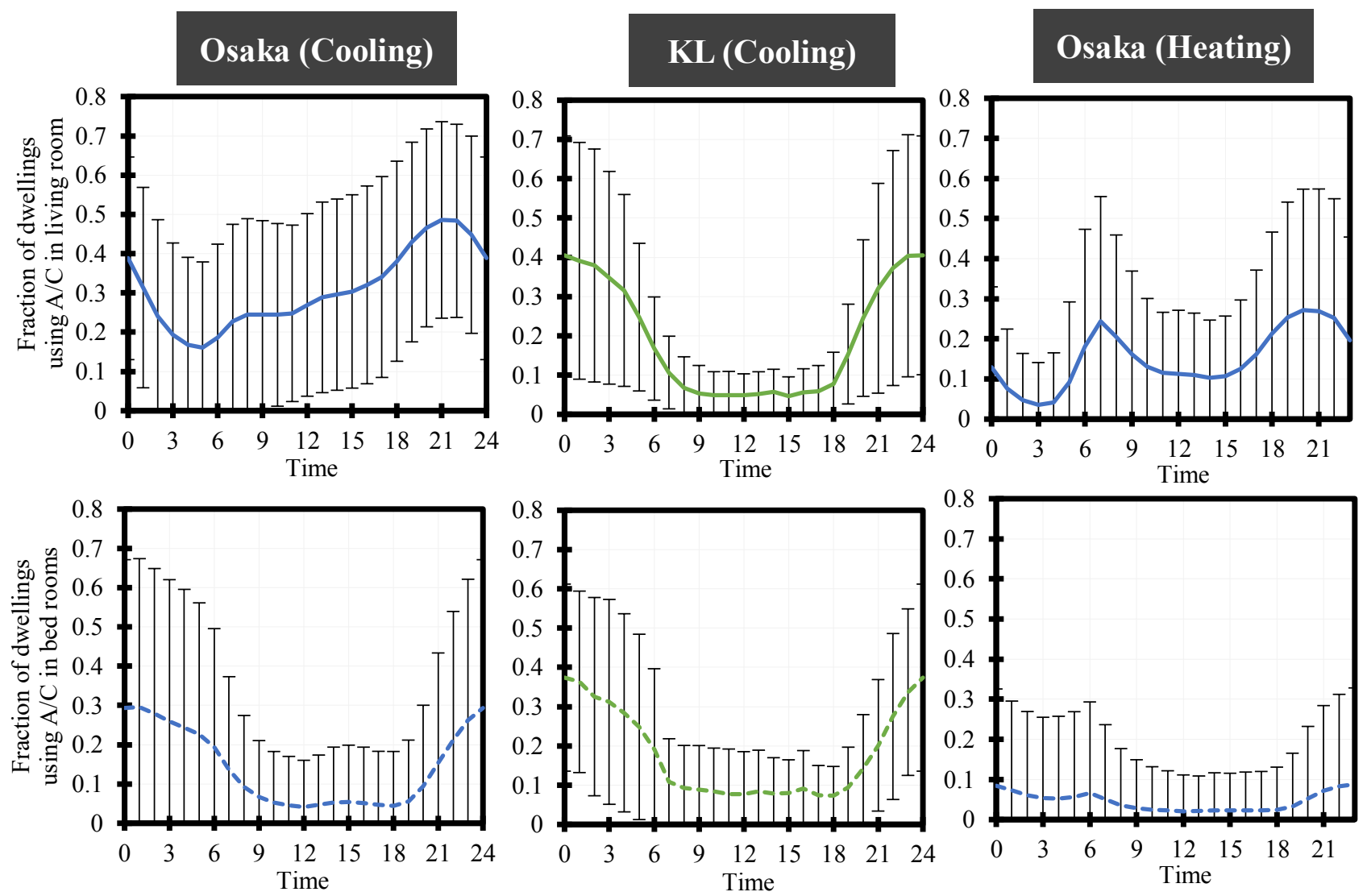

Fig. 3. Daily variation in the fraction of dwellings using A/C in Osaka and KL, by A/C unit location. The error bars indicate the standard deviation among dwellings 
With regard to the standard deviation among dwellings shown by error bars in the figures, the data of cooling in Osaka range from 0.15 to 0.4 . In particular, the deviation is large at midnight in bedrooms. On the other hand, those in $\mathrm{KL}$ are from 0.05 to 0.1 at daytime for $\mathrm{A} / \mathrm{C}$ in living room and the largest deviation is 0.3 , which can be seen at 0 am in living room. This indicates that the occupant behaviour for each dwelling in KL was less diverse compared to that in Osaka. In heating, the variation among dwellings is relatively larger at morning and evening in living room, and at midnight in bed rooms.

\section{Characteristics of the A/C load of multiple dwellings}

\subsection{Calculation of the A/C load of multiple dwellings}

Figure 4 indicates time-variations for aggregated $\mathrm{A} / \mathrm{C}$ loads for a group of dwellings with various sizes. The dwellings used for this calculation were randomly sampled from the total population, the electricity consumption every minute of the selected dwellings was averaged and converted into the aggregated $\mathrm{A} / \mathrm{C}$ load assuming a constant value for the coefficient of performance (COP). The COP of all A/Cs in Osaka's dwellings was assumed as 5 for cooling and 6 for heating, because the APF of A/Cs installed in the living rooms is 4.7 to 6.7 (Section 2). The COP of $\mathrm{A} / \mathrm{Cs}$ in $\mathrm{KL}$ was assumed as 3, which is the minimum required performance standard in Malaysia [12].

The vertical axis indicates cooling load per dwelling. The monitoring data spans three days, from 7 August to 9 August 2013 and from 13 March to 15 March 2016 for Osaka and KL, respectively. Unlike the dataset for Osaka, the measurement of electricity consumption in the dwellings of $\mathrm{KL}$ was not conducted simultaneously. Therefore, the aggregated $\mathrm{A} / \mathrm{C}$ load of multiple dwellings in the KL dataset was calculated based on only the data for 10 dwellings observed from 12 March 2016 to 28 April 2016. As can be seen from the data for both cities, the A/C load of a single dwelling shows a high frequency with strong fluctuations due to the mechanical control of inverters to adjust the indoor temperature to a set-point temperature. In addition, the cooling load exceeds $750 \mathrm{~W}$ immediately after the switching on event to respond the initial thermal load. As the number of dwellings for
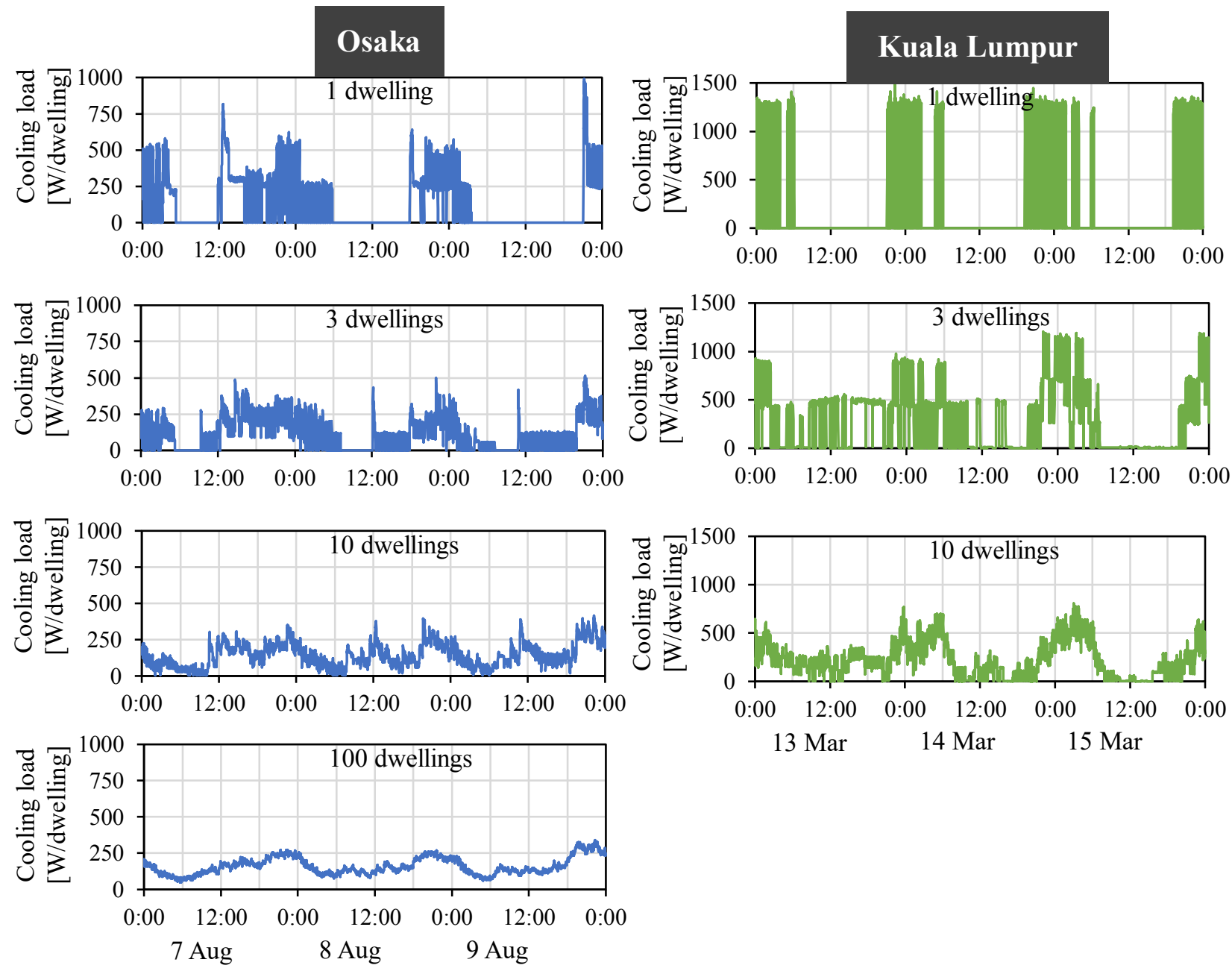

Fig. 4. Time-variations for averaged $\mathrm{A} / \mathrm{C}$ loads per dwelling over time for many sizes of dwelling units. 

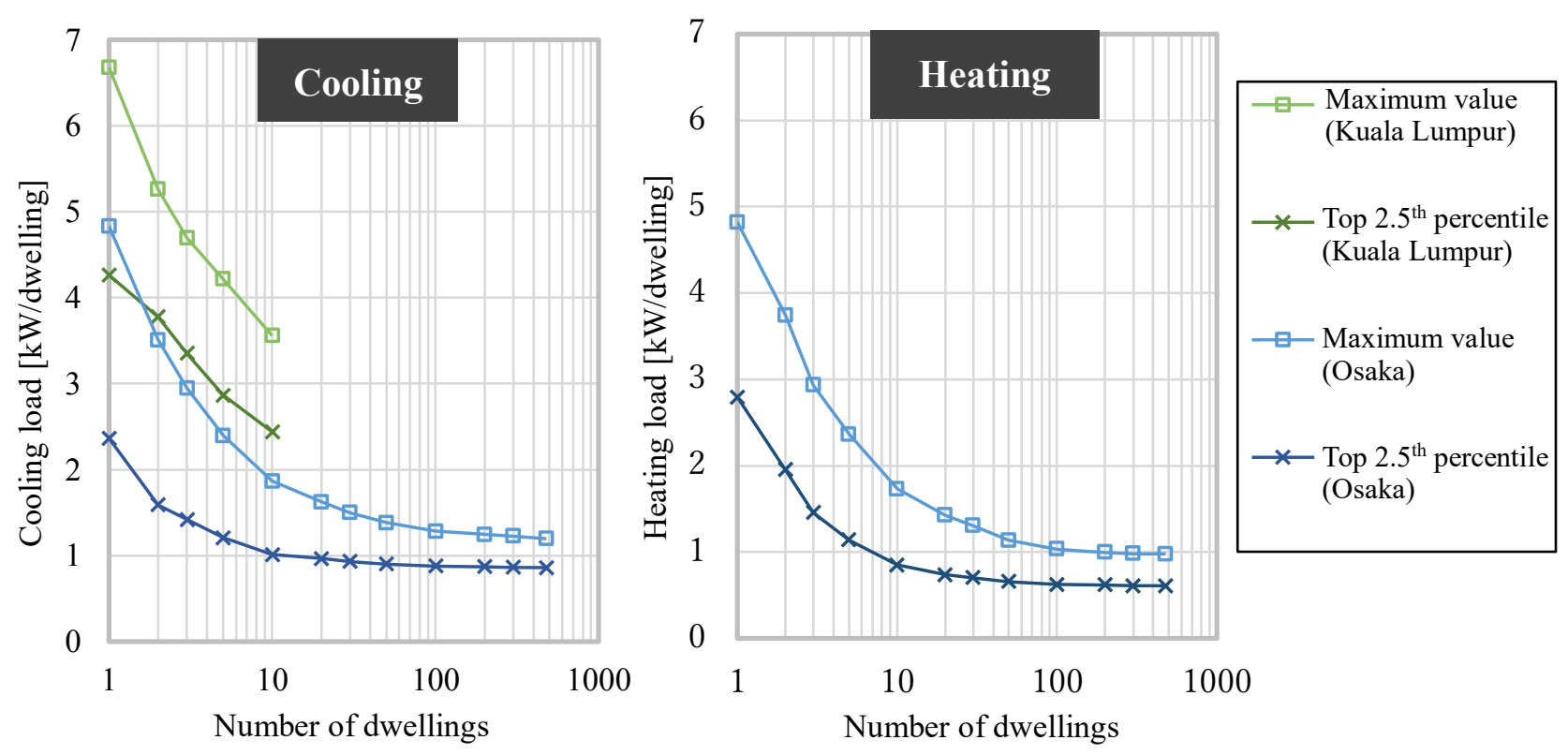

Fig. 5. The effect the number of dwellings has on the peak and top $2.5^{\text {th }}$ percentile of average $\mathrm{A} / \mathrm{C}$ loads per dwelling.

aggregation increases, both short-term fluctuations and peak cooling load are dampened and long-term patterns such as daily variation becomes obvious. This is because that the diverse patterns of $\mathrm{A} / \mathrm{C}$ use among different dwellings are smoothened out each other.

\subsection{Peak of the aggregated A/C load of multiple dwellings}

Figure 5 shows the effect of the number of dwellings on the aggregation on the peak load and the top $2.5^{\text {th }}$ percentile of A/C load, which were calculated based on the following process and converted to the $\mathrm{A} / \mathrm{C}$ load per dwelling. For the aggregation of a group of $n$ dwellings, random sampling of $n$ dwellings was repeated without replacement, and statistics, i.e. the maximum and top $2.5^{\text {th }}$ percentile were calculated for each sampled group. As a result, for $n=5$, the number of randomly selected groups of dwellings is 2 for the KL dataset, which includes 10 dwellings, and 97 for Osaka dataset, which includes 489 dwellings.

For both cooling and heating in Osaka, the peak load per dwelling drastically decreases as the number of dwellings increases, and the peak load for 10-dwelling groups accounts for close to $40 \%$ of that for a single dwelling. This is because the time-pattern for the $\mathrm{A} / \mathrm{C}$ load of each dwelling cancelled each other out due to the diversity of occupant behaviour. Both short-term and strong fluctuations by inverters as well as the rapid upstroke which coincides with the initiation of $\mathrm{A} / \mathrm{C}$ were smoothed out. On the other hand, the peak load of 10 dwellings in KL accounts for $55 \%$ of the single dwelling peak load, because the occupant behaviour for each dwelling in KL was less diverse compared to that in Osaka (see Figure 3).
Regarding the comparison between the $2.5^{\text {th }}$ percentile and the peak load, the difference between these statistics decreases as the number of dwellings increases. Especially, for cooling in Osaka, the peak load is twice as large as the $2.5^{\text {th }}$ percentile. This result implies that an $\mathrm{A} / \mathrm{C}$ system with a large capacity is needed to respond fully in the extremely rare event of a high $\mathrm{A} / \mathrm{C}$ load. In contrast, the peak load is 1.4 times as large as the $2.5^{\text {th }}$ percentile over 100 dwellings.

Figure 6 indicates the probability density (PD) of the time and date on which the top $2.5^{\text {th }}$ percentile of $\mathrm{A} / \mathrm{C}$ load was observed. In the data of Osaka for date, the daily average of outdoor temperature is also included. Regarding the PD of time, the variation in PD becomes evident and shows a larger peak as the number of dwellings increases. For example, the peak of PD for a single dwelling is around 0.06 ; in contrast, that for 100 dwellings exceeds 0.2 . This is because the daily peak of the $\mathrm{A} / \mathrm{C}$ load of a single dwelling is mainly determined by the upstroke associated with the initiation event. In contrast, the fraction of dwellings that use $\mathrm{A} / \mathrm{C}$ is a dominant factor in the determination of the PD of multiple dwelling units, which is also proven by the fact that the PD shows a similar time of peak to the fraction of $\mathrm{A} / \mathrm{C}$ operating dwellings shown in Figure 3. The PD of heating in Osaka exhibits two peaks in the morning and at night. The morning peak is higher than that at night, despite the same fraction of dwellings using $\mathrm{A} / \mathrm{C}$ during the time of the morning peak and night peak (see Figure 3). This difference between morning peak and night peak is caused by the lower outdoor air temperature in the morning, which results in a larger heating load compared to that in the night.

Regarding the PD of date, the variation becomes intense as the number of dwellings increase, similar to the 


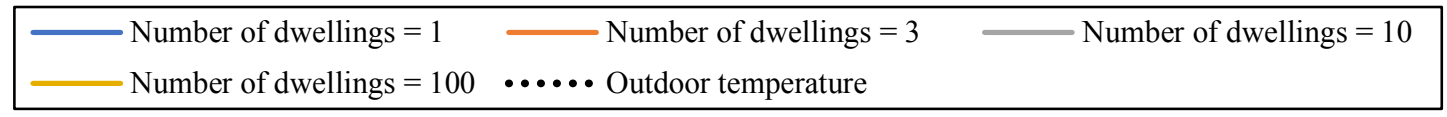

\section{Osaka (Cooling)}
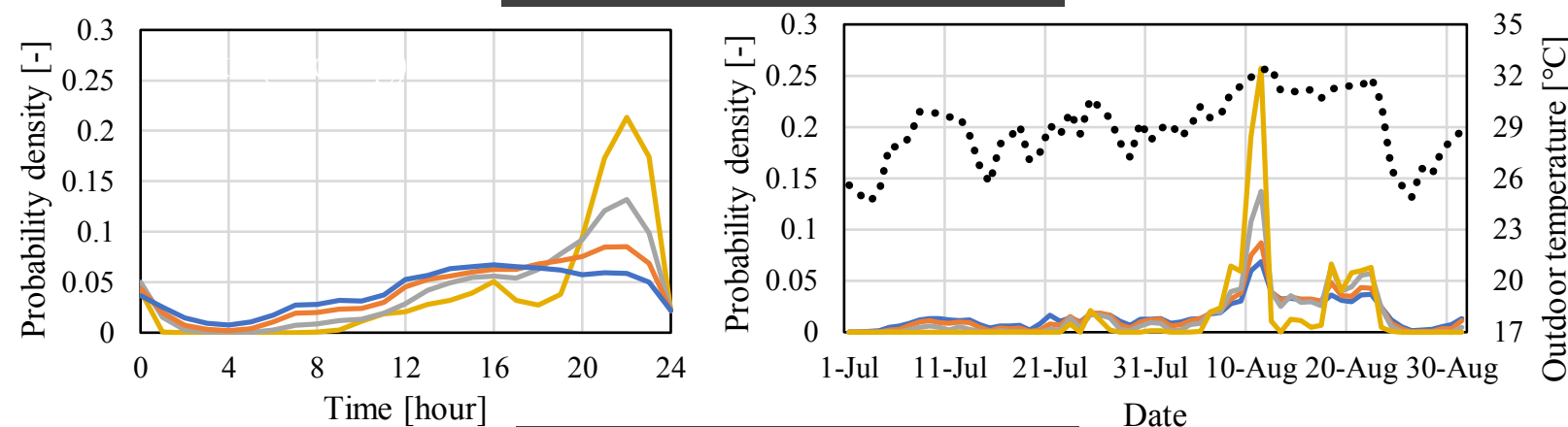

Kuala Lumpur (Cooling)
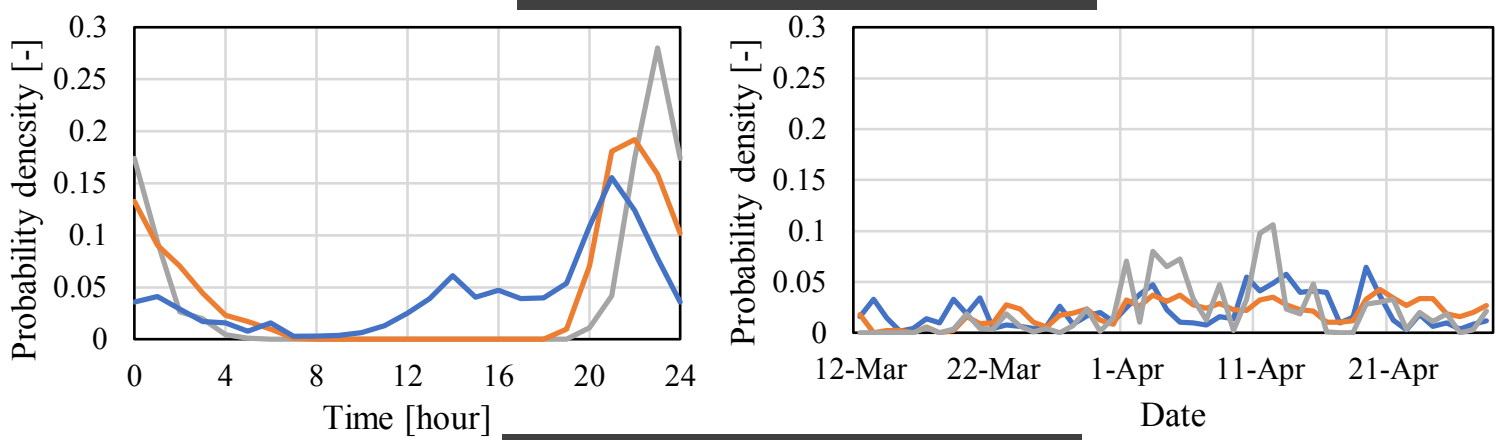

\section{Osaka (Heating)}
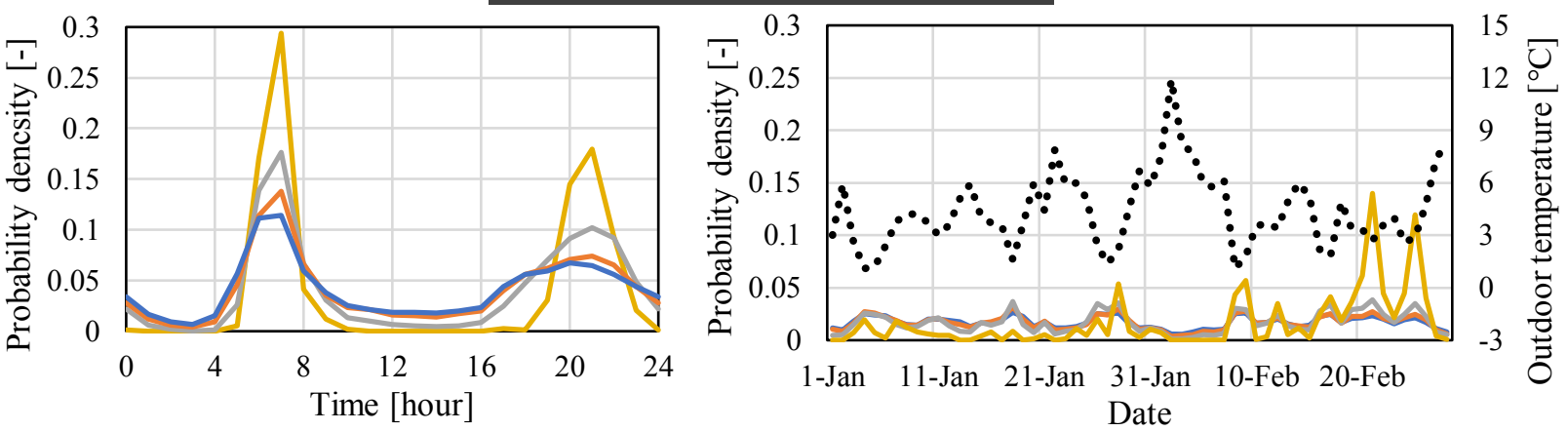

Fig. 6. The probability density of time (left) and date (right) in which top 2.5 percentile are seen.

PD of time. During cooling in Osaka, the PD on 10 August is highest during the cooling period, and the outdoor temperature of the same day is also the highest. From 13 to 16 August, the PD is close to zero despite the high outdoor temperature. It is because this period Obon is the holiday season in Japan, and most occupants might have been absent from their home. Unlike the results for cooling, no obvious relationship can be seen in heating, probably due to the occupants having several device options for heating other than $\mathrm{A} / \mathrm{Cs}$.

\section{Conclusion}

The authors carried out a statistical analysis of time-series data for $\mathrm{A} / \mathrm{C}$ electricity consumption in residential buildings located in Osaka, Japan, and Kuala Lumpur, Malaysia to grasp the feature of aggregated A/C load of multiple dwellings. The findings are as follows:

- The peak of the aggregated A/C load per dwelling decreased by half as the number of dwellings increased from 1 to 10 , due to the offset of the diverse time-patterns of $\mathrm{A} / \mathrm{C}$ usage among multiple dwellings.

- The occurrence of the top $2.5 \% \mathrm{~A} / \mathrm{C}$ load shows a strong time and date dependency in the case of $\mathrm{A} / \mathrm{C}$ load aggregated by a substantial number of dwellings. This tendency facilitated the forecast of $\mathrm{A} / \mathrm{C}$ peak loads. 


\section{References}

1. B. Henrik, H.P. Kvols, S. Allan, S. Kim C, Influence of Occupants' Behaviour on the Energy Consumption of Domestic Buildings, Clima 2010, (2010)

2. J.F. Nicol, M.A. Humphreys, ASHRAE 2004, A stochastic approach to thermal comfort - occupant behaviour and energy use in buildings, ASHRAE Transactions 2004, 110(2), 554-568, (2004)

3. F. Haldi, D. Robinson, On the behaviour and adaptation of office occupants, Build Environ 43(12), 2163-2177 (2008)

4. J. Tanimoto, A. Hagishima, State transition probability for the Markov Model dealing with on/off cooling schedule in dwellings, Energy Build, 37, 181187 (2005)

5. X. Ren, D. Yan, C. Wang, Air-conditioning usage conditional probability model for residential Buildings, Build Environ, 81, 172-182 (2014)

6. X. Ren, D. Yan, T. Hong, Data Mining of Space Heating System Performance in Affordable Housing, Build Environ, 89, 1-13 (2015)

7. S. Kindaichi, D. Nishina, S. Murakawa, M. Ishida, M. Ando, Analysis of energy consumption of room air conditioners: An approach using individual operation data from field measurements, Applied Thermal Engineering, 112, 7-14, (2017)

8. A. Hagishima, R. Fukami, S.A. Zaki, N. Ikegaya, N.F.H.M. Hanip, J. Tanimoto, Cross-cultural comparison of occupants' behaviour towards cooling of residences between Japan and Malaysia, Clima 2016, 6 (2016)

9. S.A. Zaki, A. Hagishima, R. Fukami, N. Ikegaya, N. Fadhilah, Development of a model for generating airconditioner operation schedules in Malaysia, Build Environ, 122, 354-362 (2017)

10. OWL + USB : Energy Monitoring and Analysis : http:/www.theowl.com/index.php/energy-monitors/ standalone-monitors/owl-usb/ (2017)

11. Ministry of Health, Labour and Welfare : https://www.mhlw.go.jp/toukei/saikin/hw/k-tyosa/ktyosa 17/d1/02.pdf (2017) (In Japanese)

12. MS1525: Code of practice on energy efficiency and use of renewable energy for non-residential buildings, D.o.S. Malaysia, Editor (2007) 